\title{
O campo de turismo no Brasil: caracterização e análise da rede de pesquisadores e sua dinâmica regional
}

\author{
Andre Fontan Kohler ${ }^{I}$ \\ http://orcid.org/0000-0002-8291-1654
}

Luciano Antonio Digiampietri II
http://orcid.org/0000-0003-4890-1548

${ }^{I}$ Universidade de São Paulo, SP, Brasil.

Professor Doutor do Curso de Bacharelado em Lazer e Turismo,

com credenciamento pleno nos programas de pós-graduação em Gestão de Políticas Públicas e em Estudos Culturais da Universidade de São Paulo.

${ }^{\text {II }}$ Universidade de São Paulo, SP, Brasil.

Professor Associado do Curso de Bacharelado em Sistemas de Informação, com credenciamento pleno nos programas de pós-graduação em Sistemas de Informação e em Bioinformática da Universidade de São Paulo.

http://dx.doi.org/10.1590/1981-5344/4030

O objeto é o campo de turismo no Brasil, tomado como os indivíduos que, em seu currículo Lattes, declaram que atuam em turismo. Os objetivos principais são caracterizar esses indivíduos, verificar as principais instituições de formação acadêmica e atuação profissional, e identificar os principais veículos de publicação. As análises foram embasadas por métodos de análise bibliométrica e de análise de redes sociais. Os resultados indicam a existência de um campo de conhecimento fragmentado e ainda em fase de amadurecimento.

Palavras-chave: Turismo. Bibliometria. Redes sociais. 


\title{
The field of tourism in Brazil: characterization and analysis of the researchers' network and its regional dynamics
}

\begin{abstract}
We study the field of tourism in Brazil, taken as the individuals who, in their curriculum Lattes, declare they work in this field. The main objectives are to characterize these individuals, to verify the main institutions of academic formation and work, and to identify the main scientific journals. We used methods of bibliometric analysis and of social networks analysis. The results indicate the existence of a fragmented and not yet mature field of knowledge.
\end{abstract}

Keywords: Tourism. Bibliometrics. Social networks.

Recebido em 24.06.2019 Aceito em 15.06.2021

\section{Introdução}

A avaliação do avanço científico e tecnológico de um país, instituição ou grupo ocorre por meio de técnicas qualitativas e quantitativas. Essa última categoria apresentou significativa expansão, nos últimos anos, associada principalmente aos seguintes fatores: a) aumento na disponibilização de bases estatísticas com informações relacionadas a pesquisadores, grupos, artigos e patentes; e b) crescente necessidade de informações capazes de instrumentalizar decisões estratégicas, no âmbito das políticas públicas de ciência e tecnologia.

Dentre as técnicas quantitativas, destaca-se a cientometria, cujo objetivo é caracterizar os resultados das atividades científicas. Devido à particular importância das publicações científicas nessa área, a cientometria e a bibliometria estão, em grande parte, sobrepostas (ABRAMO; D'ANGELO, 2011; ZITT; BASSECOULARD, 2008).

A literatura especializada em bibliometria destaca três categorias de indicadores, a saber: a) indicadores de quantidade, que medem a produtividade de uma instituição, grupo ou pesquisador; b) indicadores de qualidade, que medem a qualidade ou performance de um determinado 
resultado; e c) indicadores estruturais, que medem conexões entre publicações, autores e áreas de pesquisa (DURIEUX; GEVENOIS, 2010). Essa última categoria agrega informações derivadas da análise de redes sociais aplicadas a conjuntos de pesquisadores e artigos científicos (DIGIAMPIETRI et al., 2015; BRITO et al., 2016).

Segundo Tribe (1997, 2010), o turismo compreende três dimensões, a saber: a) trata-se de um fenômeno social, econômico, político e cultural, que consiste no deslocamento e na permanência temporária de pessoas em locais fora de seu ambiente normal de residência e/ou trabalho, com pelo menos uma pernoite e não mais do que um ano de duração, devido aos mais variados motivos - lazer, negócios, estudos etc.; b) a educação e o treinamento em turismo, cujo elemento mais visível são os cursos de turismo; e c) o estudo do turismo, que envolve a pesquisa sobre esse fenômeno, cujo elemento mais visível é a formação de uma comunidade de docentes e pesquisadores, e que resulta na formação de um corpo de conhecimento.

Tribe (1997) defende que o estudo do turismo consiste em um campo de conhecimento, e não em uma disciplina. O estudo do turismo não apresenta uma unidade teórica nem sequer conceitual; na verdade, ele depende de métodos e conceitos desenvolvidos em outras ciências e disciplinas. Ou seja, o que une o estudo do turismo é o objeto de estudo (fenômeno - turismo), não a metodologia de pesquisa nem sequer o quadro conceitual (caso de uma disciplina).

O objeto de estudo do presente trabalho é o campo de conhecimento de turismo no Brasil, compreendido aqui como o conjunto de indivíduos que, em seu currículo Lattes, declaram que atuam em turismo (área, subárea ou especialidade).

O objetivo principal é analisar, sob os pontos de vista bibliométrico e de análise de redes sociais, o campo de turismo no Brasil. Para isso, cumpre caracterizar os indivíduos que atuam nesse campo, verificar quais são as principais instituições de formação acadêmica e de atuação profissional, e identificar quais são os principais veículos de publica ção, no Brasil e no exterior. Nas análises feitas, dá-se grande importância aos níveis de grandes regiões e de unidades da federação, inclusive em pontos como, por exemplo, a migração de pessoas (endereço natal e endereço profissional) e a rede social de coautorias entre pessoas de diferentes cidades e unidades da federação.

Koseoglu et al. (2016) realizaram uma extensa revisão de literatura sobre a bibliometria e a análise de redes sociais, no campo de turismo. Os autores destacam o expressivo crescimento da produção científica, a partir de 2008. Os três principais periódicos internacionais de turismo identificados são os Annals of Tourism Research, Tourism Management e Journal of Travel Research. Segundo os autores, ainda predominam os 
estudos de revisão de literatura e de criação de rankings de autores e instituições mais produtivos. Poucos artigos apresentaram análises conceituais relacionais, a exemplo de redes de coautoria e de co-citação.

Ainda há relativamente poucos trabalhos que avaliam o campo de turismo no Brasil; até o momento, não se tem conhecimento de um que utilizou os dados contidos na Plataforma Lattes, com a abrangência aqui apresentada. O presente artigo supre uma lacuna importante na produção científica brasileira sobre turismo, permitindo que se caracterize um campo de conhecimento em franco crescimento, nas últimas décadas.

Pensando o conjunto de autores que publicam nos três principais periódicos internacionais de turismo - Annals of Tourism Research, Tourism Management e Journal of Travel Research -, Racherla e Hu (2010) apontam que há três hipóteses para explicar o porquê de a rede de colaboração ser tão fragmentada nesse campo, a saber: a) a relativa imaturidade do campo de conhecimento; b) o caráter multidisciplinar da pesquisa no campo de turismo; e c) a (ainda) limitada cooperação internacional entre autores.

No Brasil, há vários dados que apontam o crescimento do campo de turismo, nas últimas décadas. Já há mais de 20 periódicos científicos brasileiros de turismo, às vezes conjugados a outras áreas, como marketing e administração. Têm havido também a criação e consolidação de vários programas de pós-graduação stricto sensu; em 2002, foi criada a Associação Nacional de Pesquisa e Pós-Graduação em Turismo (ANPTUR).

Em 1999, o Conselho Nacional de Desenvolvimento Científico e Tecnológico (CNPq) lançou e padronizou o Currículo Lattes. Em poucos anos, a Plataforma Lattes passou a agregar pesquisadores de todo o país, e, atualmente, reúne mais de 5 milhões de currículos pessoais, incluindo informações de grupos de pesquisa e instituições em um repositório único e padronizado (PLATAFORMA LATTES, 2018). Esse repositório contém dados cadastrais dos indivíduos, com sua trajetória acadêmica, projetos de pesquisa, publicações, orientações etc. Essas informações permitem diferentes análises do cenário acadêmico nacional, envolvendo análises globais ou direcionadas a nichos temáticos, disciplinas e campos de conhecimento.

Este artigo está organizado da seguinte forma. A seção 2 traz a revisão de literatura, e é imediatamente seguida pela descrição da metodologia de pesquisa. A seção 4 apresenta e discute os resultados da pesquisa. Ela é imediatamente seguida pela seção 5 , com as considerações finais do artigo. 


\section{Revisão de literatura}

Mena-Chalco e Cesar Junior (2009) desenvolveram e disponibilizam publicamente uma ferramenta de software livre, chamada script Lattes, destinada à extração e compilação automática de informações dos currículos Lattes. A partir de uma lista de identificadores dos currículos, a ferramenta gera relatórios em formato $\mathrm{HTML}$, incluindo o detalhamento das produções bibliográficas, técnicas e artísticas, orientações, projetos de pesquisa, prêmios e títulos. Adicionalmente, a ferramenta produz redes sociais de coautoria, contendo os pesquisadores selecionados e um mapa de geolocalização dos pesquisadores.

Digiampietri et al. (2015) desenvolveram ferramentas para copiar, organizar e analisar grandes volumes de dados de currículos extraídos da Plataforma Lattes. Os autores analisaram mais de 1,2 milhão de currículos, responsáveis pela publicação de mais de 10 milhões de artigos científicos. Os autores descrevem a base de dados formada a partir desses currículos, enfatizando a distribuição dos pesquisadores por áreas de atuação e as relações de coautoria entre eles.

No campo de turismo, diferentes estudos têm utilizado informações disponíveis na Plataforma Lattes. Biz et al. (2008) analisam a produção científica dos orientadores dos programas de pós-graduação em turismo e hotelaria. Nesse trabalho, os autores destacam o baixo número de publicações internacionais produzidas entre 2004 e 2007, inclusive, e a baixa quantidade de alunos com bolsa de pós-graduação.

Tavares et al. (2009) utilizam informações do Diretório de Grupos de Pesquisa da Plataforma Lattes para analisar grupos de pesquisa relacionados à temática "gestão do lazer". Eles identificam que grande parte dos grupos está ligada ao campo de turismo, e está localizada na Região Sul do Brasil, responsável pela mais alta produção de artigos científicos completos sobre o assunto.

Tomando como objeto o conjunto de artigos publicados nos três principais periódicos internacionais de turismo (Annals of Tourism Research, Tourism Management e Journal of Travel Research), no período 1996-2005, Racherla e Hu (2010) apontam que poucos autores se envolvem em grande número de coautorias. Mais de $75 \%$ dos autores publicaram apenas um artigo; a rede do campo de turismo é formada por pequenos grupos dispersos, que trabalham em relativo isolamento do restante da rede, e por um grupo de pesquisadores centrais, que são altamente conectados, e publicam frequentemente nos principais periódicos do campo. Isso é similar aos resultados apresentados por Jogaratnam et al. (2005) e McKercher (2008).

Koseoglu et al. (2016) reúnem e analisam 190 artigos de bibliometria e análise de redes sociais, publicados no período 1988-2015, em nove periódicos dos campos de turismo e de hospitalidade. Eles 
percebem que 157 (82,6\% do total) consistem em estudos de revisão (review studies), baseados em revisão de literatura, estatística básica e/ou análises qualitativas. Da seleção, há apenas 24 artigos que trazem estudos avaliativos, como, por exemplo, aqueles que constroem rankings, ao passo que nove trabalhos são estudos relacionais (relational studies), que trabalham com a análise de redes (palavras-chave e referências bibliográficas, principalmente).

Nos últimos anos, a análise bibliométrica e de redes sociais no turismo tem se concentrado na avaliação de revistas científicas e na construção de rankings dos autores, instituições e países que nelas publicam (MULET-FORTEZA et al., 2019; KIRILENKO; STEPCHENKOVA, 2018). Em alguns casos, o foco é em um tema ou área dentro do campo, caso de Garrigos-Simon, Narangajavana-Kaosiri e Lengua-Lengua (2018), os quais estudam a sustentabilidade no turismo. Nesses casos, a regra é o objeto de estudo ser um conjunto de periódicos do campo de turismo.

O foco na análise da produção veiculada em revistas científicas pode ser verificado no aparecimento e crescimento de estudos dedicados a avaliar, única e exclusivamente, um periódico específico, casos de Kumar, Sureka e Vashishtha (2020) (Journal of Heritage Tourism), Guzeller e Celiker (2019) (Asia Pacific Journal of Tourism Research), García-Lillo, Ubeda-García e Marco-Lajara (2016) (International Journal of Hospitality Management) e Strandberg et al. (2018) (Tourism and Hospitality Research).

No caso dos principais periódicos internacionais de turismo e de hospitalidade, a literatura aponta que a América Latina - e, em particular, - Brasil - tem baixa participação no total de artigos publicados (MORENO GIL et al., 2020; PARK et al., 2011).

Moreno-Gil et al. (2020) verificam que há uma grande correlação entre o local onde a pessoa trabalha, e a região e o país nos quais ela desenvolve sua pesquisa, no caso de artigos publicados em sete periódicos de turismo da América Latina (cinco do Brasil, um do México e um da Argentina). Verifica-se que tem havido um grande crescimento da pesquisa em turismo na América Latina, a julgar pelo aumento do número de revistas científicas e de artigos nelas publicados. Contudo, há ainda baixa publicação de artigos de autores vinculados a instituições de fora da América Latina (MORENO-GIL et al., 2020).

\section{Materiais e métodos}

A partir de um conjunto de quase cinco milhões de currículos Lattes, obtidos em 31 de dezembro de 2016, foram identificados 23.352 currículos de pessoas que declararam atuar na área, subárea ou especialidade de turismo. 
As informações utilizadas para a análise, extraídas desses currículos, foram as seguintes: a) local de nascimento; b) áreas de atuação; c) formação acadêmica; d) atuação profissional; e e) produção bibliográfica.

Uma caracterização inicial dos dados foi realizada, calculando-se o total, a média e a distribuição de diferentes medidas. As análises realizadas foram embasadas por métodos de análise bibliométrica (TAGUE-SUTCLIFFE, 1992; SPINAK, 1998; HIRSCH, 2005) e de análise de redes sociais (SCOTT, 2009; POBLACION et al., 2009; WASSERMAN; FAUST, 2009; PRELL, 2012). Por fim, as correlações de Pearson e Spearman foram utilizadas, para se avaliar a relação entre algumas medidas.

As redes sociais produzidas nesse trabalho correspondem a redes de coautoria, nas quais duas pessoas estão ligadas, se, e somente se, tenham participado da publicação de uma mesma produção científica. A metodologia utilizada para a identificação das relações de coautoria e criação das redes sociais é a proposta por Digiampietri et al. (2012).

Dois pesquisadores são considerados coautores, se, e somente se, seus currículos contenham, ao menos, uma publicação em comum. Dois registros de publicação são considerados a mesma obra, se, e somente se, tenham sido cadastrados com os mesmos tipos, título e ano, e apresentem listas de autores compatíveis entre si (DIGIAMPIETRI et al., 2012). No presente artigo, essa compatibilidade é verificada considerando-se, única e exclusivamente, o sobrenome dos autores.

Nessas redes, cada nó corresponde a uma pessoa, e cada aresta indica a relação de coautoria entre dois indivíduos. Para fins de análise, 28 redes sociais foram construídas, uma para cada unidade da federação e uma para o conjunto de todos os indivíduos da amostra; por questão de limitação de espaço, apenas essa última é reproduzida no artigo.

O Quadro 1 traz as métricas de análise de redes sociais utilizadas no presente estudo: 
Quadro 1. Métricas de análise de redes sociais

\begin{tabular}{|c|c|}
\hline Métrica & Definição \\
\hline Número de nós & Quantidade de pessoas em cada rede. \\
\hline Número de arestas & Quantidade de relações entre pares de pessoas. \\
\hline Densidade & Quantidade de relações existentes na rede, em \\
\hline Coeficiente de agrupamento & $\begin{array}{l}\text { possivel de relações para uma rede de mesmo tamanho. } \\
\text { Medida de transitividade das relações da rede. Seu valor varia de zero (rede }\end{array}$ \\
\hline Tamanho do componente gigante & $\begin{array}{l}\text { Número de nós no componente gigante. Este é o maior componente conexo da } \\
\text { rede, isto é, o maior componente no qual todos os nós estão ligados, direta ou } \\
\text { indiretamente }\end{array}$ \\
\hline $\begin{array}{l}\text { Porcentagem de nós no } \\
\text { componente gigante }\end{array}$ & $\begin{array}{l}\text { Indiretamente. } \\
\text { É igual ao número de nós no componente gigante dividido pelo número de nós na } \\
\text { rede. }\end{array}$ \\
\hline $\begin{array}{l}\text { Número de componentes com } \\
\text { mais de um nó }\end{array}$ & Onentes conexos gue nossuem dois ou mais nós \\
\hline ninhos mínimos & $\begin{array}{l}\text { Média dos caminhos minimos (ou geodésicos) entre todos os pares de individuos } \\
\text { de cada componente conexo da rede. }\end{array}$ \\
\hline Diâmetro & $\begin{array}{l}\text { Tamanho do maior caminho minimo entre dois individuos de um mesmo } \\
\text { componente conexo. }\end{array}$ \\
\hline Centralização de grau & Medida que indica a importância do individuo mais importante de uma rede, em \\
\hline Centralização de proximidade & $\begin{array}{l}\text { relacão aos demais (considerando o grau dos individuos). } \\
\text { Medida que indica a importância do individuo mais importante de uma rede, em } \\
\text { relação aos demais (considerando a distância entre os individuos). }\end{array}$ \\
\hline Centralização de intermediação & $\begin{array}{l}\text { Medica que indica a importância do individuo mais importante de uma rede, em } \\
\text { relação aos demais (considerando-se a quantidade de vezes que cada individuo } \\
\text { aparece nos caminhos minimos entre todas as pessoas). }\end{array}$ \\
\hline
\end{tabular}

Fonte: elaboração própria.

\section{Resultados}

Dos 23.352 currículos, 22.945 são de pessoas nascidas no Brasil (98,26\%). As demais (407) nasceram em 59 países diferentes. Desses, destaca-se o conjunto de países cujo idioma oficial - ou pelo menos um deles - é o português ou espanhol, que correspondem a 296 estrangeiros $-72,73 \%$ do total.

Da amostra, 9.474 pessoas $(40,57 \%$ do total) declararam um endereço profissional. Destes, $98,5 \%$ estão no Brasil. A Tabela 1 apresenta a distribuição das pessoas da amostra que possuem endereço profissional no Brasil, bem como, para cada unidade da federação, sua participação na composição da população e do produto interno bruto (PIB). Observa-se uma correlação bastante alta entre a distribuição dos endereços profissionais, nos dados da amostra, e a distribuição da população brasileira nas unidades da federação $(0,96)$, bem como com a participação no PIB brasileiro dos estados e do Distrito Federal $(0,94)$. 
Tabela 1. Endereços natal e profissional e respectiva participação na população e no PIB, por unidade da federação e grande região

\begin{tabular}{|c|c|c|c|c|}
\hline $\begin{array}{l}\text { Unidade Fiscal / } \\
\text { Grande Região }\end{array}$ & Endereço Natal & Endereço Profissional & $\begin{array}{l}\text { Porcentagem da População } \\
\text { Brasileira }^{*}\end{array}$ & Porcentagem do PIB** \\
\hline SP & $19,70 \%$ & $18,00 \%$ & $21,70 \%$ & $32,40 \%$ \\
\hline MG & $10,10 \%$ & $8,90 \%$ & $10,20 \%$ & $8,70 \%$ \\
\hline RJ & $8,20 \%$ & $7,60 \%$ & $8,10 \%$ & $11,00 \%$ \\
\hline PR & $6,90 \%$ & $7,10 \%$ & $5,50 \%$ & $6,30 \%$ \\
\hline $\mathrm{SC}$ & $4,60 \%$ & $6,70 \%$ & $3,40 \%$ & $4,20 \%$ \\
\hline RS & $7,20 \%$ & $6,00 \%$ & $5,50 \%$ & $6,40 \%$ \\
\hline BA & $6,10 \%$ & $5,80 \%$ & $7,40 \%$ & $4,10 \%$ \\
\hline PE & $4,80 \%$ & $4,10 \%$ & $4,60 \%$ & $2,60 \%$ \\
\hline $\mathrm{CE}$ & $4,50 \%$ & $4,00 \%$ & $4,40 \%$ & $2,20 \%$ \\
\hline GO & $3,10 \%$ & $3,40 \%$ & $3,20 \%$ & $2,90 \%$ \\
\hline DF & $1,80 \%$ & $3,30 \%$ & $1,40 \%$ & $3,60 \%$ \\
\hline $\mathrm{RN}$ & $3,00 \%$ & $3,20 \%$ & $1,70 \%$ & $1,00 \%$ \\
\hline PA & $3,40 \%$ & $2,90 \%$ & $4,00 \%$ & $2,20 \%$ \\
\hline MS & $1,80 \%$ & $2,60 \%$ & $1,60 \%$ & $1,80 \%$ \\
\hline $\mathrm{AM}$ & $2,20 \%$ & $2,60 \%$ & $1,90 \%$ & $1,40 \%$ \\
\hline SE & $1,40 \%$ & $2,00 \%$ & $1,10 \%$ & $0,60 \%$ \\
\hline MT & $1,40 \%$ & $1,90 \%$ & $1,30 \%$ & $1,40 \%$ \\
\hline PB & $2,30 \%$ & $1,90 \%$ & $1,90 \%$ & $0,90 \%$ \\
\hline MA & $2,20 \%$ & $1,80 \%$ & $3,40 \%$ & $1,30 \%$ \\
\hline $\mathrm{AL}$ & $1,70 \%$ & $1,70 \%$ & $1,60 \%$ & $0,80 \%$ \\
\hline PI & $1,40 \%$ & $1,10 \%$ & $1,60 \%$ & $0,70 \%$ \\
\hline TO & $0,30 \%$ & $0,80 \%$ & $0,70 \%$ & $0,50 \%$ \\
\hline ES & $0,80 \%$ & $0,80 \%$ & $1,90 \%$ & $2,00 \%$ \\
\hline $\mathrm{RR}$ & $0,30 \%$ & $0,60 \%$ & $0,20 \%$ & $0,20 \%$ \\
\hline RO & $0,40 \%$ & $0,50 \%$ & $0,90 \%$ & $0,60 \%$ \\
\hline AP & $0,30 \%$ & $0,40 \%$ & $0,40 \%$ & $0,20 \%$ \\
\hline $\mathrm{AC}$ & $0,10 \%$ & $0,10 \%$ & $0,40 \%$ & $0,20 \%$ \\
\hline Sudeste & $38,80 \%$ & $35,40 \%$ & $41,90 \%$ & $54,00 \%$ \\
\hline Nordeste & $24,60 \%$ & $23,30 \%$ & $26,70 \%$ & $13,70 \%$ \\
\hline Sul & $18,70 \%$ & $19,80 \%$ & $14,40 \%$ & $16,80 \%$ \\
\hline Centro-Oeste & $9,70 \%$ & $11,20 \%$ & $7,50 \%$ & $9,70 \%$ \\
\hline Norte & $8,10 \%$ & $10,30 \%$ & $9,50 \%$ & $5,80 \%$ \\
\hline
\end{tabular}

Fonte: elaboração própria, com dados do Instituto Brasileiro de Geografia e Estatística (2017a, 2017b) para a porcentagem da população brasileira e porcentagem do PIB.

Destaca-se, ainda a partir dos dados dessa tabela, que o Distrito Federal possui representação na amostra correspondente a mais do que duas vezes sua participação na população brasileira (3,3\% e 1,4\%, respectivamente). Isso é explicado pela concentração de serviços públicos federais (ministérios, secretarias etc.) no Distrito Federal, como refletem os dados. Os dados do Estado de Sergipe também chamam a atenção, dado que, frente a sua participação no PIB brasileiro $(0,6 \%$ "do total), há uma quantidade expressiva de indivíduos que tem lá seu endereço profissional ( $2 \%$ do total) - mais do que três vezes, em números percentuais. No Rio Grande do Norte, as porcentagens relativas a endereço natal e a endereço profissional são desproporcionalmente altas, quando comparadas a sua participação na população e no PIB do Brasil.

Apesar de as pessoas trabalharem em mais de 1.000 cidades diferentes, mais da metade delas dedararam, em seu endereço profissional, apenas 22 delas. Com exceção de Foz de Iguaçu e de Juiz de Fora e de Brasília (capital federal), todas são capitais de estado. Isso ilustra o fato de que a capital federal e as capitais de unidades da 
federação ainda concentram as instituições de ensino superior públicas e privadas, mesmo que, nos anos 2000 e 2010, tenha havido a abertura de novas universidades e faculdades no interior dos estados. Apenas as capitais dos cinco estados menos populosos da Região Norte (Rio Branco, Porto Velho, Boa Vista, Macapá e Palmas) e do estado mais pobre do país (Teresina), pelo critério de renda per capita, ficam de fora.

A Tabela 2 mostra a migração (endereço natal - endereço profissional) entre as unidades da federação.

Tabela 2. Migrações entre unidades da federação - endereço natal (origem) e endereço profissional (destino)

\begin{tabular}{|c|c|c|c|c|c|c|c|c|c|c|c|c|c|c|c|c|c|c|c|c|c|c|c|c|c|c|c|c|c|}
\hline & 4 & 8 & $\sum$ & $\dot{z}$ & $\overleftrightarrow{m}$ & 已ี & 羕 & $=$ & 8 & $\frac{\pi}{2}$ & $\Sigma$ & $\frac{2}{2}$ & $\bar{\Sigma}$ & 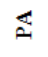 & $\stackrel{m}{2}$ & $\stackrel{19 x}{2}$ & f & $\stackrel{\simeq}{2}$ & $\approx$ & z & & శี & $\cong$ & Un & $\sqrt{n}$ & $\hat{\hbar}$ & $?$ & 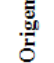 & 吾 \\
\hline $\mathrm{AC}$ & & 0 & 0 & 0 & 1 & 0 & 0 & 0 & 0 & 0 & 1 & 0 & 0 & 0 & 0 & 0 & 0 & 0 & 0 & 1 & 1 & 0 & 0 & 1 & 0 & 0 & 0 & 5 & -1 \\
\hline AL & & & 0 & 0 & 2 & 0 & 0 & 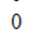 & 0 & 0 & 1 & 0 & 0 & 0 & 2 & 2 & 0 & 1 & 1 & 1 & 1 & & 1 & 2 & 8 & & 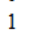 & 27 & 10 \\
\hline AM & 0 & 0 & & 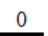 & 0 & 2 & 0 & 0 & 1 & 0 & 2 & 0 & 0 & 3 & 0 & 1 & 0 & 2 & 2 & 0 & 0 & 3 & J & 0 & 0 & 1 & 0 & 20 & 26 \\
\hline AP & & 0 & 1 & & & 0 & 1 & . & 0 & 0 & 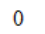 & 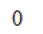 & 0 & 1 & 0 & 0 & 0 & 0 & 1 & 0 & 0 & & 0 & 0 & 0 & 3 & 0 & 8 & 7 \\
\hline BA & c & 4 & 2 & 0 & 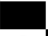 & 4 & 9 & 1 & 3 & 0 & 8 & 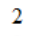 & 1 & 1 & 3 & 15 & 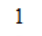 & 0 & 7 & 3 & 0 & 1 & 1 & 4 & 12 & 15 & 3 & 100 & 7 \\
\hline$C E$ & ( & 1 & 3 & 0 & 2 & & 6 & 0 & 1 & 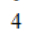 & 2 & 0 & 0 & 2 & 4 & & 3 & 1 & 5 & $y$ & 0 & & 1 & & & 4 & 0 & 58 & 0 \\
\hline DF & 0 & 0 & 0 & 0 & 3 & 2 & & 0 & 5 & 1 & 1 & 0 & 1 & 2 & 1 & 1 & 2 & 1 & 1 & 1 & 0 & 0 & 0 & 1 & 1 & 4 & 2 & 30 & 146 \\
\hline ES & & 1 & 0 & 0 & 4 & 0 & 1 & & 0 & 0 & 4 & 1 & 0 & 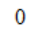 & 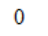 & 0 & & 0 & & & & & & & & 3 & 0 & & -7 \\
\hline GO & 0 & 0 & 0 & 0 & 4 & 2 & 14 & 0 & 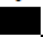 & 3 & 5 & 3 & 5 & 0 & 1 & 1 & & 2 & 5 & 1 & 1 & & 1 & 1 & 1 & 6 & 8 & 66 & 14 \\
\hline IA & 0 & 0 & 5 & 0 & 2 & 2 & 4 & 0 & 2 & 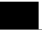 & 0 & 1 & 1 & 1 & 0 & 1 & 4 & 0 & 2 & 0 & 1 & 2 & 0 & 3 & 1 & 2 & 4 & 39 & -7 \\
\hline IG & 1 & 2 & 3 & 0 & 14 & 4 & 29 & 11 & 19 & 1 & & 1 & 4 & 3 & 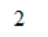 & 3 & 1 & 11 & 35 & 1 & 0 & & 3 & 9 & 2 & 45 & 6 & 211 & -106 \\
\hline MS & 0 & 0 & 1 & 0 & 0 & 0 & 1 & 0 & 2 & 1 & 1 & 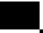 & 5 & 0 & 1 & 1 & 0 & s & 1 & 0 & 0 & & 1 & 3 & 0 & - & & 30 & 62 \\
\hline IT & 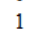 & 0 & 0 & 0 & 0 & 0 & 1 & 0 & 1 & 0 & 0 & 5 & & 2 & 1 & 0 & 0 & 2 & 1 & 0 & & & 0 & 0 & 1 & 5 & & 23 & 45 \\
\hline $\mathrm{PA}$ & 0 & 0 & 10 & 10 & 2 & 2 & 4 & 0 & 2 & 2 & 1 & 0 & 0 & & 0 & 1 & 1 & 1 & 4 & 3 & & & & & 1 & 7 & 3 & 57 & -26 \\
\hline PB & 0 & 0 & 2 & 0 & 2 & 3 & 5 & 0 & 0 & 1 & 3 & 1 & 0 & 0 & & 10 & 1 & 0 & 2 & 7 & 0 & & 0 & & 3 & 4 & 0 & 47 & -3 \\
\hline & & 8 & 2 & 0 & 7 & 9 & 10 & 0 & 1 & 1 & 0 & 0 & 2 & & & & 2 & 2 & & & & & & & & & 3 & 85 & -26 \\
\hline PI & 0 & 0 & 0 & 0 & 0 & 3 & - & 0 & 0 & 4 & 1 & 0 & 1 & 0 & 2 & & & 0 & 0 & 1 & 0 & & & & 0 & & 1 & 22 & 1 \\
\hline PR & 1 & 2 & 2 & 0 & 5 & 1 & 7 & 0 & 5 & 0 & 6 & 15 & 19 & 1 & 1 & & & & $\&$ & 4 & 1 & 3 & 5 & 30 & 2 & 3 & 1 & 155 & -13 \\
\hline RJ & 0 & 8 & 5 & 0 & 18 & 6 & 25 & 9 & 4 & 3 & 22 & 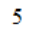 & 2 & 2 & 4 & & & & & & 4 & & & 12 & 0 & 29 & c & 179 & -37 \\
\hline RN & 0 & 2 & 0 & 0 & . & 2 & 5 & 0 & 0 & 1 & - & 0 & 1 & 0 & & & & & & & & 1 & 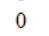 & & 2 & & & 25 & 34 \\
\hline RO & 0 & 0 & 0 & 0 & 0 & 0 & 0 & 0 & 2 & 0 & 1 & 0 & 1 & 0 & 0 & & & & & & & & 0 & 1 & & & & 13 & 0 \\
\hline RB & 0 & 0 & 0 & 0 & 0 & 0 & 0 & 0 & 0 & 0 & 0 & 0 & 0 & & & & & & & & & & & & & & & & 28 \\
\hline RS & 0 & 0 & 4 & 2 & 9 & & 14 & 4 & 7 & 1 & 10 & 5 & 2 & 2 & 3 & & & 25 & & & & & & & 1 & & & 208 & -157 \\
\hline SC & 0 & 0 & 2 & 0 & 3 & 0 & 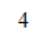 & 0 & 2 & 1 & 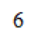 & 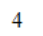 & 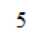 & & 0 & & & 30 & & & & & & & & 10 & & 88 & 98 \\
\hline St & 0 & 2 & 0 & 0 & 0 & 0 & 3 & 0 & 0 & 1 & 0 & 0 & 0 & 0 & 0 & & & 0 & 1 & 1 & & & & & & & 1 & 14 & 38 \\
\hline SP & 0 & 7 & 4 & 3 & 27 & 10 & 24 & 4 & 2 & 7 & 30 & 47 & 18 & 8 & 10 & & & 53 & 43 & 11 & & & 16 & 36 & & & & 414 & -194 \\
\hline TC & 0 & 0 & 0 & 0 & 0 & 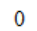 & 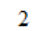 & 0 & 2 & 0 & 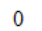 & 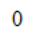 & 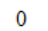 & 0 & 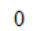 & & & 1 & 0 & 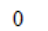 & & & & & & & & $\varepsilon$ & 38 \\
\hline estino & 4 & 37 & 46 & & 107 & & 176 & & 80 & & & & 68 & 31 & 44 & & & & & & & & & 186 & & 220 & & 1953 & 0 \\
\hline
\end{tabular}

Fonte: elaboração própria.

O Estado de São Paulo é, ao mesmo tempo, os principais origem e destino de migração, o que era esperado, dado que é a mais importante (população e PIB) unidade da federação. No campo de turismo, tem um sistema consolidado de instituições de ensino superior, no nível de graduação e pós-graduação. Sua capital é o maior centro emissor e principal destino turístico brasileiro, e concentra a sede das principais firmas turísticas nacionais e internacionais.

Como destino de profissionais, o Distrito Federal recebe pessoas de todo o país, o que se justifica devido à concentração de servidores públicos federais. Já Santa Catarina é o terceiro destino de profissionais (186 pessoas), mas 38,71\% deles proveem do Rio Grande do Sul. Há fortes relações de migração entre estados com origem similar, traços culturais comuns e/ou histórico de migração (geral) e colonização, a 
exemplo de Pernambuco e Paraíba, do Paraná, Mato Grosso e Mato Grosso do Sul e do Pará, Amapá e Amazonas.

Do conjunto de indivíduos que registraram um endereço profissional, $46,2 \%$ trabalham em uma instituição de ensino superior. Este valor elevado era esperado, pois os currículos da Plataforma Lattes são bastante utilizados no meio acadêmico. As dez instituições de ensino que apresentam o mais alto número de pessoas são as seguintes: a) Universidade de São Paulo (104 pessoas); b) Universidade do Vale do Itajaí (96); c) Universidade Federal do Rio Grande do Norte (72); d) Centro Universitário Senac (70); e) Universidade Federal de Minas Gerais (64); f) Universidade do Estado do Amazonas (63); g) Universidade Federal Fluminense (63); h) Universidade Federal do Pará (63); i) Universidade Federal de Pernambuco (59); e j) Universidade Federal da Paraíba (58).

Chama a atenção o fato de não haver nenhuma instituição privada nem sequer confessional, fruto do recuo do ensino de turismo nessas instituições, nos últimos 15 anos, devido à retração da demanda por profissionais formados. Há seis federais, duas estaduais, uma comunitária (Universidade do Vale do Itajaí) e uma pertencente ao assim chamado Sistema S.

Das dez instituições, todas contam com, pelo menos, um bacharelado em turismo, com exceção do Centro Universitário Senac, que oferta, na graduação, hotelaria e gastronomia, áreas afeitas ao turismo. No caso da pós-graduação lato sensu e stricto sensu, seis instituições ofertam cursos de turismo - às vezes, mais de um -, ao passo que a Universidade Federal de Minas Gerais tem um mestrado em estudos do lazer. O Centro Universitário Senac oferta cursos do tipo lato sensu de áreas afins ao turismo.

Cerca de $80 \%$ da amostra declararam atuar na grande área "Ciências Sociais Aplicadas." A única outra grande área que se destaca é "Ciências Humanas," com 11\% dos indivíduos. Como Tribe $(1997,2010)$ e Smith (1989) colocam, desde pelo menos os anos 1970, ciências como a antropologia e a sociologia têm demonstrado crescente interesse em pontos como os impactos do turismo e o padrão de interação entre turistas e residentes locais.

Quanto às áreas de atuação, 14.279 pessoas dedararam atuar em turismo. O turismo é secundado pela administração, com 4.495 indivíduos. Isso reforça a avaliação de que o turismo é um campo de conhecimento intimamente vinculado ao mercado; Tribe (1997, 2000) aponta que a produção científica voltada a aplicações no mercado de turismo tende a crescer, no conjunto do campo, devido ao interesse que esse tipo de pesquisa gera entre firmas privadas e instituições públicas. 
Em termos de formação acadêmica, 15.970 pessoas declararam possuir alguma formação ou titulação em nível superior. Destas, 9,3\% possuem o título de doutor e $24,5 \%$ o título de mestre, como mais alta titulação. Entre os doutores, 373 realizaram estágios de pósdoutoramento.

Há 13 instituições que formaram, pelo menos, mais de 200 pessoas da amostra. Há considerável intersecção entre as universidades desse grupo e as que mais aparecem como local de trabalho (endereço profissional) - seis no total. As 13 mais bem colocadas são responsáveis pela formação superior de mais de $25 \%$ das pessoas que possuem esse nível de formação, a saber: a) Pontifícia Universidade Católica (680 pessoas); b) Universidade de São Paulo (517); c) Universidade do Vale do Itajaí (424); d) Universidade Federal do Rio Grande do Norte (314); e) Universidade Federal de Pernambuco (283); f) Universidade Federal do Pará (269); g) Universidade Anhembi Morumbi (264); h) Universidade Estácio de Sá (242); i) Universidade Federal de Santa Catarina (231); j) Universidade Estadual Paulista Júlio de Mesquita Filho (225); k) Universidade Federal do Paraná (221); I) Universidade de Caxias do Sul (202); e m) Universidade Federal de Minas Gerais (201).

Infelizmente, devido à falta de padronização no cadastro das pontifícias universidades católicas, não foi possível sua identificação unívoca, o que fez com que fossem representadas como apenas uma instituição.

Chama a atenção o fato de a formação acadêmica recair sobre as instituições de ensino superior públicas, havendo apenas duas comunitárias (inclusive a Universidade de Caxias do Sul) e duas privadas, o que é mais um indicativo da atrofia do ensino de turismo, no setor privado. A Universidade Estácio de Sá conta com o mais alto número de alunos de ensino superior, no Brasil; já a Universidade Anhembi Morumbi tem o bacharelado em turismo mais antigo do país (1971), e é referência em duas áreas afins ao turismo - hospitalidade e gastronomia.

No conjunto de currículos Lattes, foi identificada a publicação de 24.291 artigos em periódicos. Apenas dez periódicos publicaram mais de $10 \%$ do total de artigos - oito brasileiros, um argentino e um espanhol. Desses, todos são do campo de turismo, sem exceção. Da $11^{0}$ à $20^{\circ}$ posição, sete títulos são do campo de turismo ou correlatos (hospitalidade e lazer). A partir da $21^{\circ}$ posição, sucedem-se periódicos das mais diversas ciências, disciplinas e campos, com destaque para os de geografia. 0 número de artigos publicados, ao longo dos anos, cresceu significativamente, de poucas dezenas, até os anos 1980, até cerca de 2.000 por ano, em 2014 e 2015. A diminuição do número de artigos publicados em 2016 (pouco menos de 1.500) está provavelmente 
relacionada à não atualização dos currículos, e não a uma queda real na produção (DIGIAMPIETRI et al., 2014).

Com base nos artigos publicados, foram produzidas redes de coautoria, nas quais cada pessoa é representada por um nó (ou ponto), e cada relacionamento de coautoria em artigos científicos é representado por uma aresta (que liga dois nós). Diversas redes foram geradas, uma para cada unidade da federação e uma para todos os pesquisadores da amostra. Adicionalmente, diferentes visualizações das redes foram produzidas, de forma a prover graficamente visões gerais delas.

A Figura 1 apresenta a rede posicionada sobre o mapa do Brasil. Nela, cada nó representa uma pessoa, e está posicionado próximo à cidade de seu endereço profissional. Os nós estão coloridos de acordo com a unidade da federação do endereço profissional da respectiva pessoa. Conforme já apresentado, as arestas representam relações de coautoria, e estão pintadas de cinza, quando correspondem a coautorias entre pessoas que trabalham em diferentes estados, ou de forma colorida, caso contrário.

A Figura 1 permite a visualização de algumas características muito interessantes dessa rede social de coautorias. Primeiro, percebe-se uma clara relação centro-periferia entre a Região Norte e o restante do país. Os indivíduos dessa grande região pouco colaboram entre si, ao contrário de o que é facilmente perceptível no Nordeste, Sudeste e Sul. É provável que isso se deva ao fato de ainda haver relativamente poucos cursos de pósgraduação stricto sensu na Região Norte, principalmente nível doutorado, e que as coautorias deem-se com os orientadores e membros de grupos de pesquisa localizados em outras grandes regiões do país, com destaque para o Nordeste e o Sudeste.

Segundo, ao passo que os indivíduos se concentram nas capitais, no Norte, Nordeste e Centro-Oeste, as regiões Sudeste e Sul têm polos importantes de produção científica no interior, com exceção do Espírito Santo. Isso se deve, inclusive, à existência de universidades públicas estaduais e federais em várias cidades importantes do interior desses estados, já consolidadas e com programas de pós-graduação stricto sensu.

A Figura 2 representa a rede de todas as pessoas da amostra que possuem, pelo menos, uma relação de coautoria - os nós isolados foram removidos. As pessoas que não possuem endereço profissional no Brasil são representadas por nós da cor cinza. Há 2.763 indivíduos com produção e com, pelo menos, uma relação de coautoria. Há um componente gigante com 2.069 pessoas e 274 componentes conexos menores (contendo de duas a dez pessoas). 
Figura 1. Rede social de coautorias entre os pesquisadores da amostra pesquisadores geolocalizado, de acordo com seu endereço profissional

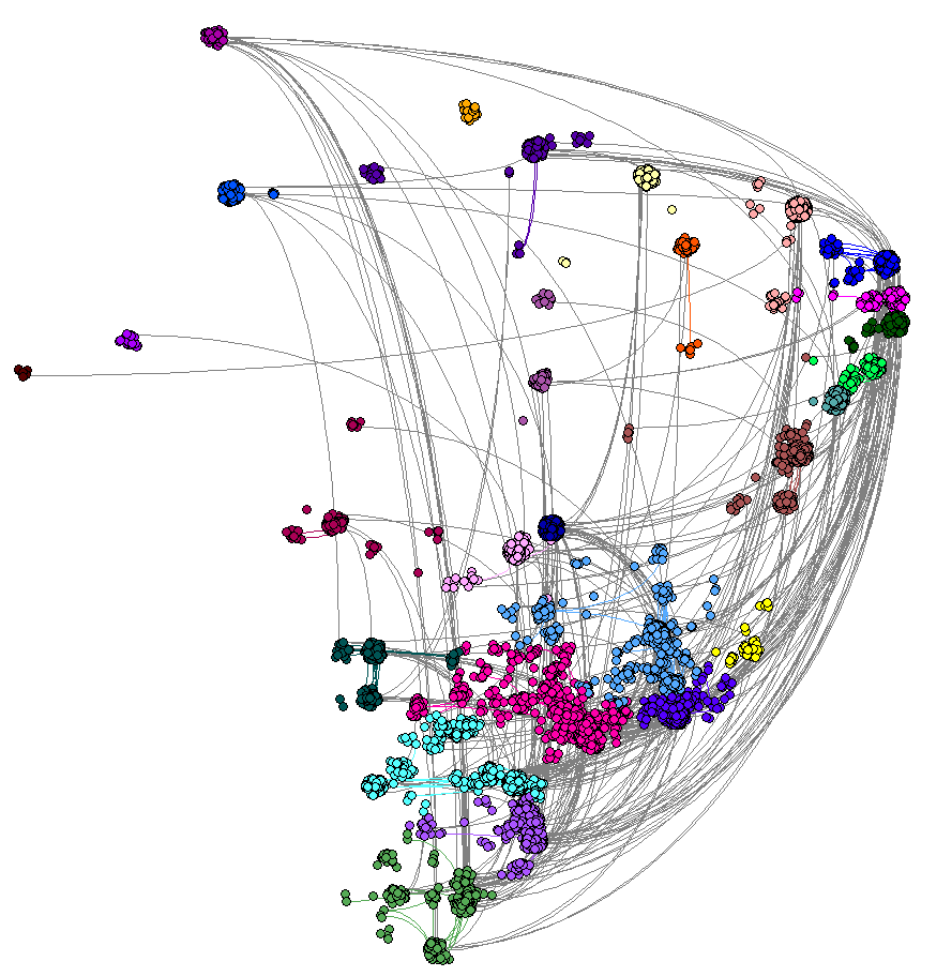

Fonte: elaboração própria. 
Figura 2. Rede social de coautorias entre os pesquisadores da amostra, excluindo-se os nós isolados

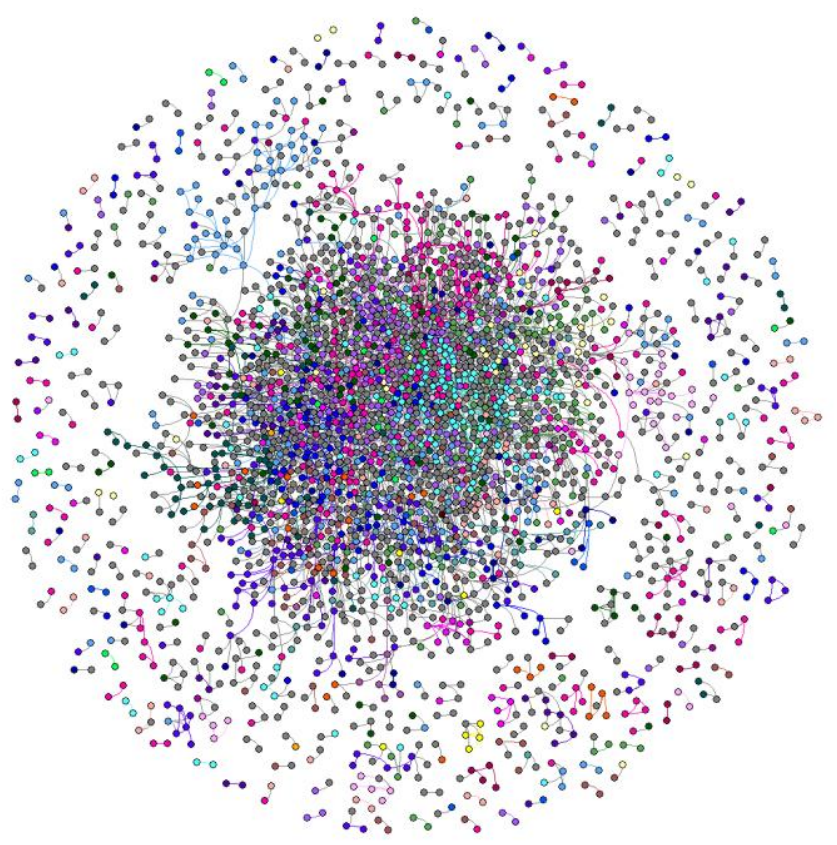

Fonte: elaboração própria.

A Tabela 3 apresenta algumas métricas das 27 redes estaduais e da rede completa. Destaca-se que as pessoas foram relacionadas à unidade da federação de seu endereço profissional, no caso das redes estaduais. $\mathrm{Na}$ "rede total," todas as pessoas da amostra foram consideradas. 
Tabela 3. Métricas de redes sociais, por unidade da federação, grande região e rede total

\begin{tabular}{|c|c|c|c|c|c|c|c|c|c|c|c|c|}
\hline 苞 & ió & 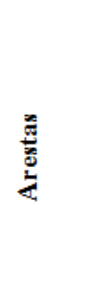 & 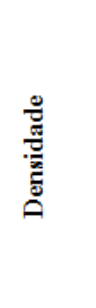 & 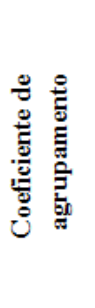 & 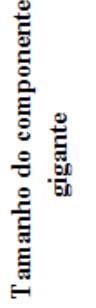 & 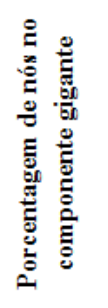 & 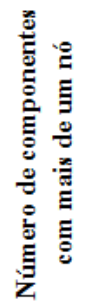 & 茪 & 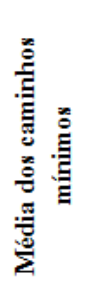 & 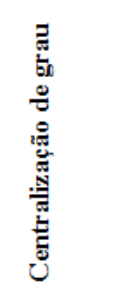 & 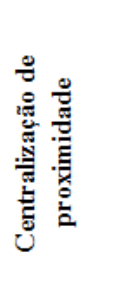 & 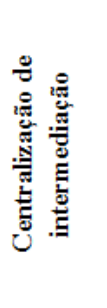 \\
\hline SP & 1.680 & 213 & $0,02 \%$ & 0,187 & 97 & $5,77 \%$ & 24 & 14 & 5,67 & 0,00938 & 0,00007 & 0,00155 \\
\hline MG & 827 & 150 & $0,04 \%$ & 0,213 & 61 & $7,38 \%$ & 23 & 14 & 5,29 & 0,01409 & 0,00017 & 0,00295 \\
\hline RJ & 705 & 104 & $0,04 \%$ & 0,14 & 45 & $6,38 \%$ & 21 & 9 & 3,99 & 0,01379 & 0,00018 & 0,00238 \\
\hline PR & 662 & 183 & $0,08 \%$ & 0,202 & 82 & $12,39 \%$ & 11 & 7 & 3,3 & 0,04001 & 0,00037 & 0,00709 \\
\hline $\mathrm{SC}$ & 625 & 138 & $0,07 \%$ & 0,109 & 82 & $13,12 \%$ & 10 & 13 & 4,68 & 0,02493 & 0,00041 & 0,00776 \\
\hline RS & 562 & 121 & $0,08 \%$ & 0,245 & 55 & $9,79 \%$ & 12 & 11 & 4,69 & 0,01706 & 0,00034 & 0,00405 \\
\hline BA & 538 & 38 & $0,03 \%$ & 0,225 & 16 & $2,97 \%$ & 11 & 7 & 2,92 & 0,0165 & 0,0001 & 0,00057 \\
\hline $\mathrm{PE}$ & 384 & 68 & $0,09 \%$ & 0,373 & 26 & $6,77 \%$ & 7 & 9 & 3,67 & 0,0278 & 0,00033 & 0,0029 \\
\hline $\mathrm{CE}$ & 372 & 28 & $0,04 \%$ & 0,243 & 13 & $3,49 \%$ & 11 & 4 & 2,24 & 0,01577 & 0,00017 & 0,00054 \\
\hline GO & 320 & 31 & $0,06 \%$ & 0,042 & 16 & $5,00 \%$ & 4 & 5 & 2,28 & 0,04641 & 0,00029 & 0,00193 \\
\hline DF & 312 & 26 & $0,05 \%$ & 0,375 & 7 & $2,24 \%$ & 7 & 3 & 1,66 & 0,02197 & 0,00012 & 0,00023 \\
\hline $\mathrm{RN}$ & 300 & 86 & $0,19 \%$ & 0,157 & 51 & $17,00 \%$ & 7 & 10 & 4,29 & 0,02818 & 0,0011 & 0,00905 \\
\hline PA & 267 & 37 & $0,10 \%$ & 0,517 & 6 & $2,25 \%$ & 11 & 3 & 1,44 & 0,02527 & 0,00013 & 0,00017 \\
\hline $\mathrm{AM}$ & 244 & 5 & $0,02 \%$ & 0 & 3 & $1,23 \%$ & 4 & 2 & 1,17 & 0,00806 & 0,00007 & 0,00003 \\
\hline MS & 243 & 63 & $0,21 \%$ & 0,143 & 26 & $10,70 \%$ & 5 & 12 & 4,15 & 0,03092 & 0,00077 & 0,00574 \\
\hline SE & 189 & 46 & $0,26 \%$ & 0,222 & 21 & $11,11 \%$ & 5 & 9 & 4,02 & 0,04528 & 0,00109 & 0,00647 \\
\hline MT & 180 & 22 & $0,14 \%$ & 0,231 & 6 & $3,33 \%$ & 10 & 3 & 1,59 & 0,01539 & 0,0003 & 0,00025 \\
\hline PB & 178 & 30 & $0,19 \%$ & 0,194 & 8 & $4,49 \%$ & 8 & 4 & 1,71 & 0,03764 & 0,00042 & 0,00057 \\
\hline MA & 164 & 27 & $0,20 \%$ & 0,162 & 19 & $11,59 \%$ & 4 & 7 & 3,44 & 0,04092 & 0,00133 & 0,00872 \\
\hline $\mathrm{AL}$ & 160 & 14 & $0,11 \%$ & 0,462 & 6 & $3,75 \%$ & 4 & 3 & 1,56 & 0,03664 & 0,00039 & 0,0004 \\
\hline PI & 106 & 12 & $0,22 \%$ & 0 & 4 & $3,77 \%$ & 5 & 3 & 1,53 & 0,02642 & 0,00049 & 0,00035 \\
\hline ES & 78 & 4 & $0,13 \%$ & 0,6 & 4 & $5,13 \%$ & 1 & 2 & 1,33 & 0,03763 & 0,00099 & 0,00068 \\
\hline TO & 74 & 8 & $0,30 \%$ & 0 & 7 & $9,46 \%$ & 1 & 4 & 2,19 & 0,06553 & 0,00219 & 0,00411 \\
\hline $\mathrm{RR}$ & 52 & 4 & $0,30 \%$ & 0 & 3 & $5,77 \%$ & 2 & 2 & 1,25 & 0,05581 & 0,00146 & 0,00078 \\
\hline RO & 46 & 1 & $0,10 \%$ & - & 2 & $4,35 \%$ & 1 & 1 & 1 & 0,02126 & 0,00096 & 0 \\
\hline AP & 39 & 0 & $0,00 \%$ & - & 1 & $2,56 \%$ & 0 & - & - & - & - & - \\
\hline $\mathrm{AC}$ & 9 & 0 & $0,00 \%$ & - & 1 & $11,11 \%$ & 0 & - & - & - & - & - \\
\hline Sudeste & 3.290 & 568 & $0,01 \%$ & 0,18 & 241 & $7,33 \%$ & 60 & 21 & 8,51 & 0,00506 & 0,00004 & 0,00224 \\
\hline Nordeste & 2.165 & 313 & $0,01 \%$ & 0,232 & 107 & $4,94 \%$ & 53 & 16 & 6,48 & 0,00587 & 0,00005 & 0,00131 \\
\hline Sul & 1.849 & 530 & $0,03 \%$ & 0,169 & 272 & $14,71 \%$ & 24 & 13 & 5,57 & 0,01538 & 0,00016 & 0,00957 \\
\hline $\begin{array}{l}\text { Centro- } \\
\text { Oeste }\end{array}$ & 1.055 & 145 & $0,03 \%$ & 0,133 & 26 & $2,46 \%$ & 25 & 12 & 3,6 & 0,01397 & 0,00004 & 0,00035 \\
\hline Norte & 957 & 149 & $0,03 \%$ & 0,222 & 67 & $7,00 \%$ & 25 & 11 & 5,08 & 0,01118 & 0,00014 & 0,00214 \\
\hline $\begin{array}{l}\text { REDE } \\
\text { TOTAL }\end{array}$ & 23.352 & 4.271 & $0,00 \%$ & 0,169 & 2.069 & $8,86 \%$ & 1.627 & 21 & 7,86 & 0,00191 & 0,00001 & 0,00121 \\
\hline
\end{tabular}

Fonte: elaboração própria.

A primeira coluna de dados da tabela apresenta a quantidade de nós (número de pessoas) em cada unidade da federação; já a segunda apresenta o número de relacionamentos de coautoria entre as pessoas de cada rede (arestas). Observa-se uma correlação muita alta entre o número de nós e o número de arestas nas redes estaduais (superior a $0,88)$. A rede de São Paulo é a maior em número de nós e de arestas; já a rede de Minas Gerais é a terceira maior em número de nós e a segunda em número de arestas. As redes do Acre e do Amapá são as menores em número de nós, e não possuem nenhuma aresta entre seus nós.

A densidade representa a razão entre o número de arestas de uma rede e seu número máximo possível de arestas (isto é, o número de 
arestas caso todos os nós fossem ligados uns aos outros). Redes de coautoria não costumam ser muito densas. A rede total possui densidade igual a 0,002\%. Nas redes estaduais, há uma correlação de postos de Spearman bastante elevada, entre a densidade e o número de nós $(-0,8)$. As redes do Acre e do Amapá não possuem arestas, e, consequentemente, têm densidade igual a zero. Em seguida, a rede menos densa é a de São Paulo. Destaca-se, ainda, a rede do Amazonas que, apesar de não ser uma das maiores redes, é a quarta menos densa. Dentre as dez maiores redes em número de nós, a que é mais densa é a de Pernambuco.

O coeficiente de agrupamento ou de clusterização mede a transitividade das relações em uma rede; isto é, dados três nós $A, B$ e $C$, caso $A$ se relacione com $B$, e $B$ se relacione com $C$, o coeficiente medirá a probabilidade de $A$ e $C$ também estarem relacionados. Em grupos fechados (por exemplo, orientadores de um programa de pós-graduação), o coeficiente de agrupamento costuma medir a maturidade da rede, pois, com o passar do tempo, é esperada a criação de relações de coautoria transitivas. Porém, em redes mais diversas e dinâmicas, esta medida pode ter diferentes interpretações. O coeficiente de agrupamento da rede total é de apenas 0,169. Destacam-se a rede de Goiás, com coeficiente de 0,6, e a do Pará, com coeficiente de 0,517.

Um conceito bastante avaliado em redes de coautoria é o componente gigante, que é o maior componente conexo de uma rede. Após o coeficiente de agrupamento, as três métricas seguintes da Tabela 3 são relacionadas ao componente gigante. O tamanho do componente das redes estaduais está fortemente relacionado ao tamanho de cada rede (correlação superior a 0,83). Destaca-se que o componente gigante da rede total possui 2.069 nós; já o maior das redes estaduais é o de São Paulo, com 97 nós. A grande diferença de tamanho do componente da rede total indica que as várias relações entre pessoas de diferentes estados servem para unir diferentes componentes, formando um componente gigante mais de 20 vezes maior do que qualquer componente estadual.

A presença de uma grande porcentagem dos nós de uma rede, em seu componente gigante, costuma estar associada a seu amadurecimento, e indica a presença de um fluxo de informações entre um número grande de indivíduos da rede. Na rede total, apenas 8,86\% dos nós pertencem ao componente gigante. Destacam-se a rede de Goiás, com mais de $20 \%$ de seus nós no componente gigante, e a rede do Amazonas, com apenas $1,23 \%$.

O número de componentes com mais de um nó numa rede indica quantos grupos separados de coautores existem nela. Destaca-se que, na 
rede total, há 274 grupos, a grande maioria composta por dois ou três nós.

O diâmetro mede a maior distância entre dois nós de um mesmo componente conexo. Na rede total, o diâmetro é igual a 21 , isto é, há dois nós para os quais o menor caminho, que liga um ao outro, é composto por outros 19 nós. As redes de Minas Gerais e de São Paulo são as estaduais com maior diâmetro (igual a 14). Entre as dez maiores redes, a do Ceará é a que possui o menor diâmetro (igual a 3).

A média dos caminhos mínimos indica o tamanho médio entre os caminhos mínimos de todos os nós para todos os demais nós, em um componente conexo. Nas redes estaduais, em média, a distância entre os nós de cada componente conexo ficou abaixo de 6. Já para a rede total, este valor foi de 7,86, evidenciando que essa rede é pouco densa e potencialmente ainda não muito madura.

A Tabela 4 apresenta a quantidade de coautorias para quem publicou, pelo menos, um artigo de periódico, com corte para autores das 27 unidades da federação. Já a Tabela 5 traz os mesmos dados, mas tomando como corte as grandes regiões.

Tabela 4. Quantidade de coautorias entre autores de diferentes unidades da federação

\begin{tabular}{|c|c|c|c|c|c|c|c|c|c|c|c|c|c|c|c|c|c|c|c|c|c|c|c|c|c|c|c|c|}
\hline & $\stackrel{u}{z}$ & 光 & & 4 & $\underset{m}{\infty}$ & ป̛⿱宀 & 台 & प్య & ర) & 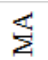 & $\sum$ & $\sum_{2}^{\pi / 2}$ & $\bar{z}$ & 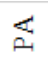 & $\stackrel{m}{2}$ & 武 & $\vec{a}$ & 㟔 & 2 & Z & $=$ & 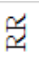 & $\stackrel{20}{\sim}$ & $U_{U}$ & Ty & चि & $\stackrel{\ominus}{\ominus}$ & 웁 \\
\hline $\mathrm{AC}$ & 0 & 0 & 0 & 0 & 0 & 1 & 0 & 0 & 0 & 0 & 0 & 0 & 0 & 0 & 0 & 0 & 0 & 0 & 0 & 0 & 0 & 0 & 0 & 0 & 0 & 0 & 0 & \\
\hline $\mathrm{AL}$ & 0 & 10 & 0 & $C_{2}$ & 0 & 0 & 1 & c & 1 & & 0 & 0 & & & & & & & & & & & & & & & & \\
\hline M & 0 & 0 & 5 & ( & 0 & 1 & 1 & 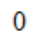 & 0 & & 1 & 3 & & & & & & & & & & & & & & & & \\
\hline AP & 0 & 0 & 0 & 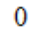 & 0 & 0 & 0 & ( & 0 & 0 & 0 & 0 & & & & & & & & & & & & & & & & \\
\hline $\mathrm{BA}$ & 0 & 0 & 0 & 0 & 3. & 1 & 0 & , & 3 & 1 & 2 & 1 & & & & & & & & & & & & & & & & \\
\hline$C E$ & 1 & 0 & 1 & C & 1 & 7 & 0 & & 1 & 0 & 2 & 0 & & & & & & & & & & & & 7 & & & & \\
\hline DF & 0 & 1 & 1 & c & & 0 & 20 & 0 & 2 & 4 & 10 & 0 & 0 & & & & & & & & & & & 17 & & & & \\
\hline ES & 0 & 0 & 0 & c & 2 & 0 & 0 & 4 & 0 & 0 & 1 & 0 & 0 & & & & & & & & & & & 0 & & & 0 & \\
\hline D & 0 & 1 & 0 & c & 3 & 1 & 2 & 0 & 24 & 0 & & 0 & 0 & & & & & & & & & & & & & & ) & \\
\hline 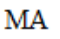 & 0 & 0 & 0 & c & & 0 & 4 & 0 & & 23 & & 0 & 0 & & & & & & & & & & & & & & & \\
\hline 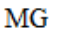 & 0 & 0 & 1 & c & & 2 & 1 & 1 & & 0 & 123 & 1 & 1 & & & & & & 35 & & & & & 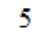 & 1 & & 0 & 36 \\
\hline MS & 0 & 0 & 3 & 0 & . & 0 & 0 & c & 0 & 0 & 1 & 35 & 1 & 2 & & 0 & & & & & & & & 4 & J & & 0 & \\
\hline $\mathrm{M}$ & 0 & 0 & 0 & c & 0 & 0 & 0 & ( & & 0 & 1 & 1 & 19 & ( & & & & & & & & & & 2 & & & 0 & \\
\hline PA & 0 & 0 & 3 & 1 & & 2 & 0 & & & 2 & 1 & 2 & 0 & 28 & & & & & & & & & & 1 & & & 0 & 5 \\
\hline PB & 0 & 0 & 0 & c & & 0 & 1 & & 0 & 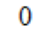 & 1 & 0 & & 0 & 24 & 3 & & & & & & & & 0 & & & 0 & 10 \\
\hline $\mathrm{PE}$ & 0 & 2 & 0 & c & & 2 & 2 & 0 & 0 & 2 & 7 & 0 & & & & 58 & 0 & & & & & & & 5 & 4 & 11 & 0 & 112 \\
\hline PI & 0 & 0 & 0 & 0 & 0 & 2 & 0 & 0 & 0 & 0 & 1 & 1 & 0 & & & 0 & 11 & 10 & & 1 & & & & 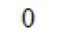 & U & & 1 & 0 \\
\hline PR & 0 & 0 & 0 & c & 2 & 2 & 4 & c & 4 & 1 & 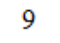 & 6 & c & & & 0 & 10 & 152 & 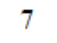 & & & & 5 & 34 & 1 & & 0 & 70 \\
\hline RJ & 0 & 0 & 2 & $c$ & 1 & 0 & 5 & 1 & 1 & 0 & 35 & 0 & 1 & & & 0 & 0 & & 90 & 1 & & & & 2 & 0 & 2 & 0 & 172 \\
\hline RN & 0 & 6 & 0 & c & & 5 & 3 & c & 0 & 0 & 1 & 1 & 0 & & & 9 & & & 1 & 74 & & & & 6 & 0 & 0 & 2 & 139 \\
\hline RO & 0 & 0 & $v$ & c & & 0 & 0 & & 1 & 0 & 0 & 0 & 0 & & & 0 & & & 0 & 0 & & & . & 1 & 0 & 0 & 0 & 3 \\
\hline $\mathrm{RR}$ & 0 & 0 & $v$ & 0 & & 1 & 1 & c & 1 & 0 & 0 & 0 & 2 & 0 & & 0 & & & 0 & 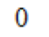 & & 3 & 9 & 2 & 1 & 0 & 0 & 21 \\
\hline RS & 0 & 1 & 2 & 0 & c & 2 & 3 & 5 & 0 & 0 & 6 & 0 & 2 & & & 2 & & & 1 & 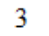 & & 9 & 101 & 28 & 1 & 22 & 2 & 197 \\
\hline SC & 0 & 2 & 2 & 0 & 4 & 7 & 17 & 0 & 1 & 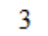 & 5 & 4 & 2 & 1 & 0 & 5 & 0 & 34 & 2 & 6 & & 2 & 28 & 115 & 6 & 15 & 0 & 262 \\
\hline $\mathrm{SE}$ & 0 & 1 & 1 & c & 5 & 1 & 0 & 0 & 0 & 1 & 1 & 0 & 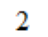 & 0 & 0 & 4 & c & & $c$ & 0 & & & 1 & 6 & 35 & & 0 & 61 \\
\hline SF & 0 & 1 & 0 & c & 5 & 6 & 8 & 0 & 3 & 0 & 21 & 18 & 3 & 1 & & 11 & & 24 & 22 & & & 0 & 22 & 15 & 1 & 174 & 1 & 347 \\
\hline TO & 0 & 0 & 0 & 0 & 2 & 0 & 3 & 0 & 0 & 0 & 0 & 0 & 0 & & 0 & 0 & & & 0 & & & & 0 & 0 & & & 0 & 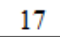 \\
\hline
\end{tabular}

Fonte: elaboração própria. 
Tabela 5. Quantidade de coautorias entre autores de diferentes grandes regiões

\begin{tabular}{lcccccc} 
& $\begin{array}{c}\text { Centro- } \\
\text { Oeste }\end{array}$ & Nordeste & Norte & Sudeste & Sul & Total \\
Centro- & 121 & 21 & 14 & 58 & 43 & 257 \\
Oeste & 21 & 260 & 40 & 46 & 55 & 422 \\
Nordeste & 14 & 40 & 124 & 17 & 33 & 228 \\
Norte & 58 & 46 & 17 & 471 & 96 & 688 \\
Sudeste & 58 & 55 & 33 & 96 & 435 & 662 \\
Sul & 43 & & & & & \\
\hline
\end{tabular}

Fonte: elaboração própria

Como as tabelas deixam claro para a maior parte das unidades da federação e para todas as grandes regiões, as relações de coautoria são predominantemente locais, mesmo que tenha havido, nos últimos anos, crescente incentivo à colaboração com autores de outras instituições nacionais e internacionais, principalmente para a progressão da carreira docente nas universidades públicas. As exceções à regra são o Acre, Amapá e Rondônia, cujo número de coautorias é muito baixo, e o Espírito Santo e Roraima, cuja principal parceria é com o Rio Grande do Sul.

Além das medidas de redes apresentadas na Tabela 3, foram calculadas métricas de rede e medidas bibliométricas de cada uma das pessoas da amostra, considerando a rede total. Três medidas de centralidade foram calculadas - de grau, de intermediação e Page Rank -, além de quatro bibliométricas ou acadêmicas (número total de artigos publicados em periódicos, número total de livros publicados ou organizados, número de orientações de doutorado concluídas e número de orientações de mestrado concluídas). A Tabela 6 apresenta a correlação entre os valores dessas sete métricas; as correlações mais intensas são representadas por células cujos fundos possuem uma cor verde mais intensa. Todas as correlações computadas foram positivas. 
Tabela 6. Correlações entre algumas métricas analisadas - indivíduos da amostra

\begin{tabular}{|c|c|c|c|c|c|c|c|}
\hline & 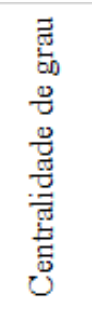 & 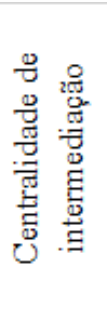 & 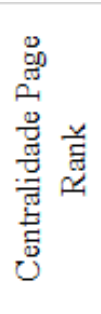 & 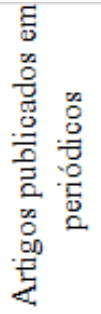 & 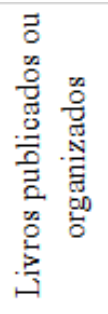 & 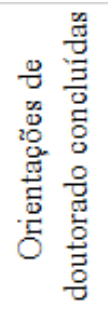 & 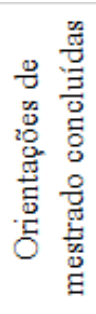 \\
\hline Centralidade de grau & 1 & 0,73 & 0,95 & 0,5 & 0,24 & 0,17 & 0,4 \\
\hline Centralidade de intermediação & 0,73 & 1 & 0,68 & 0,34 & 0,2 & 0,11 & 0,33 \\
\hline Centralidade Page Rank & 0,95 & 0,68 & 1 & 0,51 & 0,26 & 0,16 & 0,4 \\
\hline Artigos publicados em periódicos & 0,5 & 0,34 & 0,51 & 1 & 0,45 & 0,35 & 0,56 \\
\hline Livros publicados ou organizados & 0,24 & 0,2 & 0,26 & 0,45 & 1 & 0,29 & 0,42 \\
\hline Orientações de doutorado concluidas & 0,17 & 0,11 & 0,16 & 0,35 & 0,29 & 1 & 0,59 \\
\hline Orientações de mestrado concluidas & 0,4 & 0,33 & 0,4 & 0,56 & 0,42 & 0,59 & 1 \\
\hline
\end{tabular}

Fonte: elaboração própria.

Destaca-se a alta correlação existente entre as três medidas de centralidade e, em especial, entre a centralidade de grau e a centralidade Page Rank. Já o número de artigos publicados em periódicos está mais relacionado com a quantidade de orientações de mestrado concluídas do que com qualquer outra métrica.

\section{Considerações finais}

Os resultados indicam a existência de um campo de conhecimento fragmentado e ainda em fase de amadurecimento. No Brasil, parece ocorrer o que Racherla e Hu (2010) verificam para a rede de colaboração dos autores que publicam nos principais periódicos internacionais de turismo, como visto anteriormente. No Brasil, esse campo de conhecimento está em fase de construção; não se pode considera-lo maduro. A pesquisa é marcada pela multi e interdisciplinaridade, e não há cooperação internacional entre autores, pelo menos em escala relevante. Pelo que indicam os resultados, é possível afirmar que se trata de um campo de conhecimento ainda em formação, fragmentado e aberto a contribuições de autores oriundos de diversas ciências, disciplinas e outros campos de conhecimento.

Os pesquisadores encontram-se espalhados por todo o território nacional, mas ainda se concentram nas capitais e, no caso das regiões Sul e Sudeste, em alguns polos do interior. A formação acadêmica desses indivíduos depende ainda das instituições de ensino superior públicas, com baixa presença principalmente do setor privado. Os resultados mostram também que há relevante intersecção entre as principais instituições de formação e de atuação profissional. Os resultados do presente artigo reforçam a noção, levantada já por Tribe $(1997,2000)$, de que o turismo é um campo de conhecimento intimamente vinculado ao mercado. 
A distribuição dos profissionais pelo Brasil, bem como as relações de coautoria existentes na produção científica, gera duas "ausências" preocupantes, intimamente interligadas entre si. Sua base é a mesma, a saber: a escassez de profissionais e de pesquisadores de turismo, na Região Norte (principalmente nas menos populosas unidades da federação) e no interior da Região Nordeste e da Região Centro Oeste.

Do lado da prática, a ausência de profissionais que trabalhem com o turismo gera, ceteris paribus, um mais baixo desenvolvimento dessa atividade. Isso é preocupante, principalmente no caso de regiões pouco desenvolvidas, para as quais o turismo é apontado, há anos, como uma alternativa para a geração de emprego e renda. Desde pelo menos o Governo Itamar Franco (1992-1994), o turismo tem sido avaliado como uma das mais promissoras alternativas para o desenvolvimento econômico da Região Nordeste (BANCO DO NORDESTE DO BRASIL, 2005).

Do lado da pesquisa, a julgar pelos resultados de Moreno-Gil et al. (2020), a relativa escassez de indivíduos nessas regiões pode ter, como uma de suas consequências, a falta de pesquisas sobre o turismo nesses lugares. Sem profissionais nem sequer pesquisas realizadas em número suficiente, a Região Norte e o interior das regiões Nordeste e CentroOeste podem estar em um círculo vicioso, a saber: há pouco turismo, o que resulta em escassez de profissionais e pesquisas, e essa escassez limita o desenvolvimento do turismo na região.

Como colocado, há correlações muito altas entre a distribuição dos endereços profissionais, de um lado, e a distribuição da população brasileira (unidades da federação) e do PIB (unidades da federação e grandes regiões). Isso explica a distribuição dos profissionais de turismo e, provavelmente, da pesquisa e produção científica - de forma mais equilibrada entre a capital e o interior, no Sul e no Sudeste.

Mais de $10 \%$ dos artigos de periódico publicados concentram-se em apenas dez revistas - todas no idioma português ou espanhol. Nas 30 primeiras posições, não se verifica nenhuma revista no idioma inglês; é notável a ainda grande dependência, para a publicação de artigos, de periódicos da América Latina e Península Ibérica, o que corrobora os resultados de Moreno-Gil et al. (2020).

Por fim, um resultado que não surpreende, mas exige certa reflexão, é o fato de as relações de coautoria (autores) serem predominantemente locais (mesma unidade da federação ou, pelo menos, grande região). É de se esperar que isso ocorra, em virtude da facilidade de comunicação, das relações entre orientador e orientado e da proximidade de objeto de estudo, no que concerne a localização geográfica. Contudo, dada a valorização crescente de parcerias internacionais, nas avaliações de desempenho de docentes e 
pesquisadores, a predominância de parcerias locais aponta um caminho longo a se trilhar.

\section{Referências}

ABRAMO, G.; D'ANGELO, C. A. Evaluating research: from informed peer review to bibliometrics. Scientometrics, Secaucus, v. 87, n. 3, p. 499-514, jun. 2011.

BANCO DO NORDESTE DO BRASIL. Relatório final de projeto: Programa de Desenvolvimento do Turismo no Nordeste. Primeira fase. Fortaleza: BNB: 2005. Disponível em: http://www.bnb.gov.br/content/aplicacao/prodetur/downloads/docs/docu m 9 pcr i.pdf. Acesso em: 22 Set. 2011.

BIZ, A. A.; MASSUKADO, M. S.; SANTOS, A. B. S. ; MOTTER, A. Análise da produção científica dos docentes doutores dos programas de pós graduação stricto sensu em turismo e hotelaria. In: V SEMINARIO DA ASSOCIAÇÃO NACIONAL DE PESQUISA E PÓS-GRADUAÇÃO EM TURISMO, 5., 2008, Belo Horizonte. Anais eletrônicos [...]. Belo Horizonte: 2008. Disponível em: https://www.anptur.org.br/anais/anais/files/5/124.pdf. Acesso em: 20 jun. 2019.

BRITO, A. G. C.; QUONIAM, L. ; MENA-CHALCO, J. P. Exploração da Plataforma Lattes por assunto: proposta de metodologia.

TransInformação, Campinas, v. 28, n. 1, p. 77-86, jan./abr. 2016. Disponível em:

https://www.scielo.br/j/tinf/a/P3CJs6ms3HsTbQxsQKqKYps/abstract/?lang =pt. Acesso em 20 jun. 2019.

DIGIAMPIETRI, L. A. ; MENA-CHALCO, J. P; PÉREZ-ALCÁZAR, J. J.; TUESTA, E. F.; DELGADO, K. V.; MUGNAINI, R.; SILVA, G. S. Minerando e caracterizando dados de currículos Lattes. In: BRAZILIAN WORKSHOP ON SOCIAL NETWORK ANALYSIS AND MINING, 2., 2012. Anais eletrônicos [...] Curitiba: 2012. Disponível em:

https://www.researchgate.net/publication/236118307 Minerando e carac terizando dados de curriculos Lattes. Acesso em: 20 jun. 2019.

DIGIAMPIETRI, L. A. ; MUGNAINI, R. ; MENA-CHALCO, J. P.; DELGADO, K. V.; PÉREZ-ALCÁZAR, J. J. Análise macro das últimas atualizações dos Currículos Lattes. Em questão, Porto Alegre, v. 20, n. 3, p. 88-113, 2014. Disponível em: https://seer.ufrgs.br/EmQuestao/article/view/49173. Acesso em: 20 jun.2019.

DIGIAMPIETRI, L. A. ; MENA-CHALCO, J. P. ; PÉREZ-ALCÁZAR, J. J. ; TUESTA, E. F.; DELGADO, K. V.; MUGNAINI, R.; SILVA, G. S.; LIMA, J. J. S. Extração, caracterização e análises de dados de currículos Lattes. 
Revista eletrônica de sistemas de informação, Curitiba, v. 14, n. 2, p. 124, maio-ago. 2015. Disponível em:

https://seer.ufrgs.br/EmQuestao/article/view/49173. Acesso em: 20 jun. 2019.

DURIEUX, V.; GEVENOIS, P. A. Bibliometric indicators: quality measurements of scientific publication. Radiology, Oak Brook, v. 255, n. 2, p. 342-351, mai. 2010. Disponível em:

https://pubmed.ncbi.nlm.nih.gov/20413749/. Acesso em: 20 jun.2019.

GARCÍA-LILLO, F.; ÚBEDA-GARCÍA, M.; MARCO-LAJARA, B. The intellectual structure of research in hospitality management: a literature review using bibliometric methods of the journal International Journal of Hospitality Management. International journal of hospitality management, v. 52, p. 121-130, jan. 2016. Disponível em:

https://www.researchgate.net/signup.SignUp.html. Acesso em: 20 jun. 2019.

GARRIGOS-SIMON, F. J.; NARANGAJAVANA-KAOSIRI, Y.; ; LENGUALENGUA, I. Tourism and sustainability: a bibliometric and visualization analysis. Sustainability, v. 10, n. 6, 2018. Disponível em:

https://www.mdpi.com/2071-1050/10/6/1976. Acesso em: 20 jun.2019.

GUZELLER, C. O.; CELIKER, N. Bibliometrical analysis of Asia Pacific Journal of Tourism Research. Asia Pacific journal of tourism research, v. 24, n. 1, p. 108-120, 2019. Disponível em:

https://www.tandfonline.com/doi/abs/10.1080/10941665.2018.1541182?j ournalCode=rapt20. Acesso em: 20 jun.2019.

HIRSCH, J. E. An index to quantify an individual's scientific research output. Proceedings of the National Academy of Sciences of the United States of America, v. 102, n. 46, p. 16.569-16.572, nov. 2005. Disponível em: https://www.pnas.org/content/102/46/16569. Acesso em: 20 jun. 2019.

INSTITUTO BRASILEIRO DE GEOGRAFIA E ESTATÍSTICA. Contas regionais 2015: queda no PIB atinge todas as unidades da federação pela primeira vez na série. 2017a. Disponível em:

https://agenciadenoticias.ibge.gov.br/agencia-sala-de-imprensa/2013agencia-enoticias/releases/17999-contas-regionais-2015-queda-no-pibatinge-todas-asunidades-da-federacao-pela-primeira-vez-na-serie.

Acesso em: 20 jun. 2019.

INSTITUTO BRASILEIRO DE GEOGRAFIA E ESTATÍSTICA. Estimativas de população para $1^{\circ}$ de julho de 2015. 2017b. Disponível em:

https://ww2.ibge.gov.br/home/estatistica/populacao/estimativa2015/esti mativa tcu.shtm. Acesso em: 20 jun. 2019. 
JOGARATNAM, G.; CHON, Kaye; MCCLEARY, Ken; MENA, M.; YOO, J. An analysis of institutional contributors to three major academic tourism journals: 1992-2001. Tourism management, Amsterdam, v. 26, n. 5, out. 2005. Disponível em:

https://www.researchgate.net/publication/222905834 An analysis of ins titutional contributors to three major academic tourism journals 1992 -2001/link/5bd8752f92851 c6b279a06c7/download. Acesso em: 20 jun. 2019.

KIRILENKO, A. P.; STEPCHENKOVA, S. Tourism research from its inception to present day: subject area, geography, and gender distributions. PLoS $O N E$, v. 13, n. 11, 2018. Disponível em:

https://journals.plos.org/plosone/artide?id=10.1371/journal.pone.020682 0. Acesso em: 20 jun.2019.

KOSEOGLU, M. A.; RAHIMI, R.; OKUMUS, F.; LIU, J. Bibliometric studies in tourism. Annals of tourism research, Oxford, v. 61, p. 180-198, nov. 2016. Disponível em: https://www.sciencedirect.com/science/artide/abs/pii/S01607383163014 4X. Acesso em: 20 jun.2019.

KUMAR, S. ; SUREKA, R.; VASHISHTHA, A. The Journal of Heritage Tourism: a bibliometric overview since its inception. Journal of heritage tourism, v. 15, n. 4, p. 365-380, 2020. Disponível em:

https://www.tandfonline.com/doi/abs/10.1080/1743873X.2020.1754423? journalCode =rjht20. Acesso em: 20 jun. 2019.

MCKERCHER, B. A citation analysis of tourism scholars. Tourism management, Amsterdam, v. 29, n. 6, p. 1.226-1.232, dez. 2008.

Disponível em:

https://www.sciencedirect.com/science/article/abs/pii/S02615177080004 96. Acesso em: 20 jun. 2019.

MENA-CHALCO, J. P.; CESAR JUNIOR, R. M. Script Lattes: an open-source knowledge extraction system from the Lattes platform. Journal of the Brazilian computer society, Porto Alegre, v. 15, n. 4, p. 31-39, dez. 2009. Disponível em:

https://www.scielo.br/j/jbcos/a/DNqND3wQHrTHkCNW QbKx6pt/abstract/? lang=en. Acesso em: 20 jun.2019.

MORENO-GIL, S.; PARRA-LÓPEZ, E.; PICAZO-PERAL, P.; DÍAZDOMÍNGUEZ, C. The dissemination of tourism scientific research in Latin American journals. A bibliometric study. Anatolia: an international journal of tourism and hospitality research, 2020. Disponível em:

https://www.tandfonline.com/doi/abs/10.1080/13032917.2020.1795892. Acesso em: 20 jun.2019. 
MULET-FORTEZA, C.; GENOVART-BALAGUER, J.; MAULEON-MENDEZ, E. ; MERIGÓ, J. M. A bibliometric research in the tourism, leisure and hospitality fields. Journal of business research, v. 101, p. 819-827, ago. 2019. Disponível em:

https://www.sciencedirect.com/science/artide/abs/pii/S01482963183061 31. Acesso em: 20 jun.2019.

PARK, K.; PHILLIPS, W. J.; CANTER, D. D. ; ABBOTT, J. Hospitality and tourism research rankings by author, university, and country using six major journals: the first decade of the new millennium. Journal of hospitality \& tourism research, v. 35, n. 3, p. 381-416, ago. 2011. Disponível em: https://journals.sagepub.com/doi/abs/10.1177/1096348011400743. Acesso em: 20 jun.2019.

PLATAFORMA LATTES. Sobre a plataforma Lattes. 2018. Disponível em: http://memoria.cnpq.br/web/portal-lattes/sobre-a-plataforma. Acesso em: 23 ago. 2018.

POBLACION, D. A. ; MUGNAINI, R.; RAMOS, L. M. S. V. C. (Orgs.). Redes sociais e colaborativas em informação científica. São Paulo: Angellara, 2009.

PRELL, C. Social network analysis: history, theory and methodology. Thousand Oaks: SAGE, 2012.

RACHERLA, P.; HU, C. A social network perspective of tourism research collaborations. Annals of tourism research, Oxford, v. 37, n. 4, p. 1.0121.034 , out. 2010.

SCOTT, J. Social network analysis: a handbook. 2nd edition. Thousand Oaks: SAGE, 2009.

SMITH, V. L. (Ed.). Hosts and guests: the anthropology of tourism. $2^{\text {nd }}$. edition. Philadelphia: University of Pennsylvania Press, 1989.

SPINAK, E. Indicadores cienciometricos. Ciência da Informação, Brasília, v. 27, n. 2, p. 141-148, mai./ago. 1998.

STRANDBERG, C. ; NATH, A. ; HEMMATDAR, H. ; JAHWASH, M. Tourism research in the new millennium: a bibliometric review of literature in Tourism and Hospitality Research. Tourism and hospitality research, v. 18, n. 3, p. 269-285, 2018. Disponível em:

https://journals.sagepub.com/doi/abs/10.1177/1467358416642010. Acesso em: 20 jun. 2019. 
TAGUE-SUTCLIFFE, J. An introduction to informetrics. Information processing and management: an international journal, Tarrytown, v. 28, n. 1, p. 1-3, jan. 1992. Disponível em: https://dl.acm.org/doi/10.1016/0306-4573(92)90087-G. Acesso em: 20 jun. 2019.

TAVARES, G. H.; SCHWARTZ, G. M.; ALVES, H. B.; SANTIAGO, D. R. P.; KAWAGUTI, C. N. Gestão do lazer: os grupos de pesquisa em foco. Motriz, Rio Claro, v. 15, n. 3, p. 470-480, jul./set. 2009. Disponível em: https://repositorio.unesp.br/bitstream/handle/11449/20814/WOS0002704 51700001.pdf? sequence=3. Acesso em: 20 jun.2019.

TRIBE, J. The indiscipline of tourism. Annals of tourism research, Oxford, v. 24, n. 3, p. 638-657, 1997. Disponível em: https://www.sciencedirect.com/science/article/abs/pii/S01607383970002 00. Acesso em: 20 jun.2019.

TRIBE, J. Tribes, territories and networks in the tourism academy. Annals of tourism research, Oxford, v. 37, n. 1, p. 7-33, jan. 2010. Disponível em:

https://www.sciencedirect.com/science/article/abs/pii/S01607383090006 68. Acesso em: 20 jun. 2019.

WASSERMAN, S.; FAUST, K. Social network analysis: methods and applications. 19nd edition. Cambridge: Cambridge University Press, 2009.

ZITT, M.; BASSECOULARD, E. Challenges for scientometric indicators: data demining, knowledge-flow measurements and diversity issues. Ethics in science and environmental politics, Luhe, v. 8, n. 1, p. 49-60, 2008. Disponível em: https://www.sciencedirect.com/science/article/abs/pii/S01607383090006 68. Acesso em: 20 jun. 2019. 